Ball, S., Bessell, C. J. \& Mortimer, A. (1957). J. gen. Microbiol. 17, 96-103

\title{
The Production of Polyenic Antibiotics by Soil Streptomycetes
}

\author{
By S. BALL, CHRISTINE J. BESSELL AND AILEEN MORTIMER \\ Glaxo Laboratories, Ltd., Stoke Poges, Buckinghamshire
}

SUMMARY: Sixty Streptomyces isolates which produce polyene antibiotics were isolated from 25 soil samples collected in different parts of the world. Of these isolates 25 produced tetraenes, 23 produced pentaenes, 1 produced a hexaene, and 15 produced heptaenes. One isolate produced simultaneously a tetraene and a pentaene, another produced a tetraene and a heptaene, and a third produced a tetraene, a pentaene and a heptaene. The antibiotics showed activity against a wide range of fungi; the minimum inhibitory concentrations against Saccharomyces cerevisiae, Aspergillus niger, Mucor racemosus, Candida albicans, Fusarium culmorum and Trichophyton mentagrophytes are given for 10 of them. The distribution of activity between culture filtrate and mycelium is given for 14 of the antibiotics.

Hazen \& Brown (1951) described the isolation of an antifungal antibiotic (fungicidin) from a Streptomyces sp. It was active against a wide range of yeasts and other fungi, but not against bacteria. The ultraviolet (u.v.) absorption spectrum of the antibiotic in ethanol showed sharp maxima at 290, 305 and $320 \mathrm{~m} \mu$.; the frequency differences between these absorption peaks is characteristic of a series of conjugated double bonds, and the chromophoric grouping of the compound is of polyene type. Many other antibiotics of similar properties have been described in recent years in publications from the U.S.A. or Japan, and they may be grouped together on the basis of certain general properties:

(1) They inhibit the growth of a wide range of fungi, including yeasts, but are inactive against bacteria.

(2) They show a relatively high toxicity when injected into animals, but are much less toxic when given by mouth.

(3) They are of low solubility in water but dissolve more readily in aqueous solutions of the lower alcohols, and are easily soluble in aqueous pyridine.

(4) They exhibit characteristic ultraviolet absorption spectra typical of polyenic chromophores.

These properties are fairly general for the whole series of compounds, although there are some wide differences, particularly in their biological properties. Several workers have classified the polyenic antifungal antibiotics into a number of different groups according to the nature of their ultraviolet absorption spectra (Vining, Taber \& Gregory, 1955; Utahara, Okami, Nakamura \& Umezawa, 1954; Oroshnik, Vining, Mebane \& Taber, 1955; Pledger \& Lechevalier, 1956), and we have used a similar method of classification in a screening programme for antifungal antibiotics produced by various Streptomyces spp. The scheme we have used is shown in Table 1 , together with the 


\section{Table 1. The classification of polyene antibiotics according to their ultraviolet absorptions}

Amphotericins A and B: Vandeputte, Wachtel \& Stiller (1956); antibiotic 1968: Oswald, Reedy \& Randall (1956); antimycoin: Raubitschek, Acker \& Waksman (1952); ascosin: Hickey, Corum, Hidy, Cohen, Nager \& Kropp (1952); candicidin: Lechevalier, Acker, Corke, Haenseler \& Waksman (1953); candidin: Taber, Vining \& Waksman (1954); candimycin: Shibata, Honjo, Tokui \& Nakazawa (1954); chromin: Wakaki, Hamada, Akanabe \& Asahina (1953); eurocidin: Okami, Wahara, Nakamura \& Umezawa (1954); filipin: Whitfield, Brock, Amman, Gottlieb \& Carter (1955); flavacid: Takahashi (1953); fradicin: Swart, Romano \& Waksman (1950); fungichromatin : Tytell, McCarthy, Fisher, Bolhofer \& Charney (1955); fungichromin: Tytell et al. (1955); fungicidin: Hazen \& Brown (1951); mediocidin: Okami et al. (1954); rimocidin: Davisson, Tanner, Finlay \& Solomons (1951); trichomycin : Hosoya, Komatsu, Soeda \& Sonoda (1952).

\begin{tabular}{|c|c|c|c|}
\hline $\begin{array}{l}\text { Group } \\
\text { no. }\end{array}$ & $\begin{array}{l}\text { Polyene } \\
\text { type }\end{array}$ & $\begin{array}{l}\text { Absorption } \\
\operatorname{maxima}(\mathrm{m} \mu)\end{array}$ & Published antibiotics \\
\hline 1 & Tetraene & $290,305,318$ & $\begin{array}{l}\text { Fungicidin, antimycoin, rimocidin, chromin, } \\
\text { amphotericin A }\end{array}$ \\
\hline $\mathbf{2 A}$ & Pentaene & $318,333,351$ & Fungichromatin, eurocidin \\
\hline 2B & Pentaene & $325,340,358$ & Fungichromin, filipin \\
\hline 3 & Hexaene & $340,356,378$ & Mediocidin, flavacid, fradicin \\
\hline 4 & Heptaene & $360,378,405$ & $\begin{array}{l}\text { Ascosin, candicidin, candidin, trichomycin, } \\
\text { candimycin, amphotericin, B, antibiotic } \\
1968\end{array}$ \\
\hline
\end{tabular}

recorded antibiotics placed in their respective classes. During 1952-3 we carried out a screening programme for antifungal antibiotics that might be used clinically and found a wide range of polyene antibiotics from microorganisms derived from soil samples collected in different parts of the world. The details of our methods and a selection of our results are given below.

\section{METHODS}

Pure cultures of the Streptomyces spp. were isolated from agar soil dilution plates. Four media were generally used for each soil-Bennett's, potatopeptone, yeast extract and paraffin agar. The compositions of these media were:

(1) Bennett's agar medium: NZ amine (enzymic casein digest from Sheffield Chemical Co. Inc., U.S.A.) $0 \cdot 2$ g., Difco beef extract $0 \cdot 1$ g., Difco yeast extract 0.1 g., glucose 1 g., agar 1.5 g., distilled water to $100 \mathrm{ml}$.; $\mathrm{pH}$ adjusted to $7 \cdot 8 \pm 0 \cdot 1$.

(2) Potato-peptone agar medium: aqueous extract from $20 \mathrm{~g}$. of overcooked potatoes in $100 \mathrm{ml}$. of water $50 \mathrm{ml}$., peptone $0.5 \mathrm{~g}$., dipotassium monohydrogen phosphate $\mathbf{0 . 2} \mathrm{g}$., sodium chloride $\mathbf{0 . 2} \mathrm{g}$., ferrous sulphate heptahydrate $0.001 \mathrm{~g}$., agar $1.5 \mathrm{~g}$., distilled water to $100 \mathrm{ml}$.; $\mathbf{p H}$ adjusted to $6 \cdot 4 \pm 0 \cdot 1$.

(3) Yeast extract agar medium: Difco yeast extract 1 g., Evans peptone 1 g., agar 1.5 g., distilled water to $100 \mathrm{ml}$.; $\mathrm{pH}$ adjusted to $\mathbf{7 \cdot 7} \pm \mathbf{0 \cdot 1}$.

(4) Paraffin agar medium: ammonium nitrate $0.4 \mathrm{~g}$., liquid paraffin B.P. $0 \cdot 1$ g., dipotassium monohydrogen phosphate $0 \cdot 6$ g., potassium dihydrogen phosphate $0.2 \mathrm{~g}$., zinc sulphate heptahydrate $0.0049 \mathrm{~g}$., ferrous sulphate 
heptahydrate $0.00054 \mathrm{~g}$., manganous chloride tetrahydrate $0.0046 \mathrm{~g}$., copper sulphate pentahydrate $0.00025 \mathrm{~g}$., sodium borate $0.000094 \mathrm{~g}$., ammonium molybdate $0.00002 \mathrm{~g}$., agar $1.5 \mathrm{~g}$., distilled water to $100 \mathrm{ml}$.; $\mathrm{pH}$ adjusted to $7 \cdot 0 \pm 0 \cdot 1$. The medium was kept hot to melt the agar and was vigorously stirred throughout the pouring of the plates.

The medium which was successful in producing the largest number of Streptomyces colonies varied with the soil population, but paraffin agar proved to be selective for Streptomyces spp. and sometimes permitted their isolation from soils containing a high content of spreading bacteria and fungi. The number of colonies isolated from any one soil varied from about 30 to 200/g. soil.

A primary screening for antifungal activity was carried out by an agar disc method. The Streptomyces isolates were grown, in small aluminium cups with loose fitting caps, on medium 1, 2 or 3 above. After 5 days of incubation at $\mathbf{2 8}^{\circ}$, cork borer plugs of the grown cultures were transferred to test plates seeded with Saccharomyces cerevisiae and Aspergillus niger. The plates were incubated overnight at $37^{\circ}$ and the Streptomyces which showed good inhibition zones were selected for investigation of their ability to produce antibiotics in submerged aerated culture. In this secondary screening, $2 \mathrm{ml}$. portions of a $48 \mathrm{hr}$. shake-flask culture in glycerol meat broth were used to inoculate duplicate flasks of 6 different media distributed in $40 \mathrm{ml}$. quantities in $250 \mathrm{ml}$. conical flasks. These flasks were incubated on a reciprocating shaker for 5 days at $28^{\circ}$ and were sampled aseptically at daily intervals for assessment of their antibiotic content by a cup plate method using as test organism Saccharomyces cerevisiae NCTC 4614 in $2 \%(w / v)$ glucose nutrient agar with $8 \mathrm{~mm}$. diameter punched holes. When conditions had been found whereby a culture fluid gave an inhibition zone of more than $20 \mathrm{~mm}$. overall diameter, six $250 \mathrm{ml}$. flasks containing $40 \mathrm{ml}$. medium were grown for extraction purposes. The six cultures were bulked and filtered without addition of a filter aid. The separated mycelium was extracted with $2 \times 100 \mathrm{ml} .80 \%(\mathrm{v} / \mathrm{v})$ acetone in water, a stirring time of $15 \mathrm{~min}$. being allowed for each extraction. The acetone was removed from the extract by concentration to small bulk $(5 \mathrm{ml}$.) in vacuo; $20 \mathrm{ml}$. $n$-butanol was added to the aqueous extract and the water was removed by further concentration in vacuo to $5 \mathrm{ml}$. The antibiotic present in this extract was precipitated by the addition of 6 vol. diethyl ether and the resulting solid isolated by centrifugation, washed with ether to remove traces of butanol and dried in vacuo at $40^{\circ}$ for $1 \mathrm{hr}$. The bulked culture filtrate was extracted with $2 \times 100 \mathrm{ml}$. $n$-butanol, the combined butanol solutions were concentrated to $100 \mathrm{ml}$. in vacuo, and the solid was isolated as above. The solid preparations were examined in aqueous solution or in $40 \%$ $(\mathrm{v} / \mathrm{v})$ pyridine in water for antibiotic activity, but ethanolic solutions were used for measurement of the ultraviolet absorption spectra in a Unicam model SP. 500 spectrophotometer. We found it satisfactory to take the absorption spectra at the butanolic concentrate stage, for the impure nature of the samples at this stage did not preclude recognition of the polyene entities, since sharp maxima were observed. It was necessary to dilute the solutions before 
Table 2. Distribution in soils of streptomycete isolates which produce polyene antibiotics

\begin{tabular}{|c|c|c|c|c|c|c|c|}
\hline \multirow[b]{2}{*}{$\begin{array}{c}\text { Sample } \\
\text { no. }\end{array}$} & \multirow[b]{2}{*}{$\begin{array}{c}\text { Soil } \\
\text { location }\end{array}$} & \multirow{2}{*}{$\begin{array}{c}\text { No. of } \\
\text { polyene } \\
\text { producing } \\
\text { isolates }\end{array}$} & \multicolumn{5}{|c|}{ Type of polyene produced } \\
\hline & & & $\begin{array}{c}\text { Group } \\
1\end{array}$ & $\begin{array}{c}\text { Group } \\
\mathbf{2 A}\end{array}$ & $\underset{2 B}{\text { Group }}$ & $\begin{array}{c}\text { Group } \\
\mathbf{3}\end{array}$ & $\begin{array}{c}\text { Group } \\
\mathbf{4}\end{array}$ \\
\hline 1 & \multirow{8}{*}{ Argentine } & $\mathbf{3}$ & $\mathbf{2}$ & $\mathbf{3}$ & . & . & 1 \\
\hline 2 & & 1 & . & . & . & . & 1 \\
\hline 3 & & 1 & 1 & . & . & . & . \\
\hline 4 & & 2 & 2 & . & . & . & 1 \\
\hline 5 & & 2 & . & . & . & . & 2 \\
\hline 6 & & $\overrightarrow{1}$ & . & . & 1 & . & . \\
\hline 7 & & 4 & 1 & $\mathbf{3}$ & . & . & . \\
\hline 8 & & 2 & . & 2 & . & . & . \\
\hline 9$)$ & Brazil & 1 & . & . & . & . & 1 \\
\hline 10 & Burma & 9 & . & 9 & . & . & . \\
\hline 11) & \multirow{2}{*}{ Ceylon } & $\int 1$ & • & . & . & . & 1 \\
\hline 12$\}$ & & $\{1$ & 1 & . & . & . & . \\
\hline 13 & England & 1 & 1 & . & . & . & . \\
\hline 14 & India & 4 & 1 & . & . & . & $\mathbf{3}$ \\
\hline 15 & Iraq & $\mathbf{3}$ & 1 & . & . & . & 2 \\
\hline 16 & Kenya & 1 & . & . & . & . & 1 \\
\hline 17 & \multirow[t]{2}{*}{ Malaya } & 1 & . & 1 & . & . & . \\
\hline 18 & & 1 & . & . & 1 & . & . \\
\hline 19 & \multirow{3}{*}{ Nigeria } & 1 & . & . & 1 & . & . \\
\hline 20$\}$ & & $\left\{\begin{array}{l}2 \\
2\end{array}\right.$ & $\mathbf{2}$ & . & . & . & . \\
\hline 21 & & 13 & 13 & . & . & . & . \\
\hline 22 & \multirow{2}{*}{ Pakistan } & 2 & . & . & . & . & 2 \\
\hline 23) & & $\overrightarrow{1}$ & . & 1 & . & . & . \\
\hline 24$\}$ & \multirow[t]{2}{*}{ Sierra Leone } & \{ & . & . & . & 1 & . \\
\hline 25 & & 1 & . & 1 & • & . & - \\
\hline \multicolumn{2}{|c|}{ Totals } & 60 & 25 & 20 & 3 & 1 & 15 \\
\hline
\end{tabular}

Table 3. Minimum inhibitory concentrations of different polyene-antibiotic preparations against 6 fungi

Test organisms: Saccharomyces (S.) cerevisiae, Aspergillus (A.) niger, Mucor (M.) racemosus, Candida (C.) albicans, Fusarium (F.) culmorum, Trichophyton $(T$.$) mentagrophytes.$

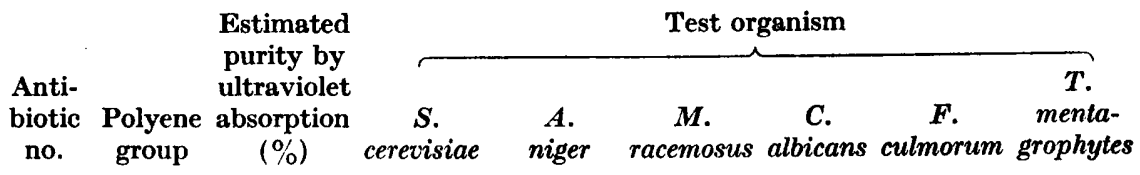

\begin{tabular}{|c|c|c|c|c|c|c|c|c|}
\hline A. 432 & 1 & $20-30$ & $1 \cdot 2$ & $4 \cdot 4$ & $4 \cdot 4$ & $\mathbf{3 \cdot 2}$ & $2 \cdot 2$ & $11 \cdot 6$ \\
\hline A. 228 & $2 A$ & $20-30$ & $3 \cdot 4$ & 4.4 & $5 \cdot 0$ & $4 \cdot 2$ & $6 \cdot 75$ & $4 \cdot 5$ \\
\hline A. 688 & $2 A$ & $20-30$ & $1 \cdot 4$ & 8.9 & 5.8 & $>3.25$ & $8 \cdot 9$ & 9.75 \\
\hline A. 695 & $2 \mathbf{A}$ & $20-30$ & $2 \cdot 2$ & $20 \cdot 0$ & $2 \cdot 2$ & $\mathbf{2 \cdot 2}$ & 6.6 & $20 \cdot 0$ \\
\hline A. 789 & $\mathbf{2 A}$ & $20-30$ & $1 \cdot 5$ & $4 \cdot 4$ & $2 \cdot 9$ & $6 \cdot 6$ & $5 \cdot 3$ & $12 \cdot 0$ \\
\hline A. 246 & $2 B$ & $80-90$ & 0.66 & 0.66 & 4.4 & $2 \cdot 2$ & $2 \cdot 2$ & $4 \cdot 4$ \\
\hline A. 772 & $2 B$ & $20-30$ & $2 \cdot 96$ & 4.44 & $10 \cdot 0$ & 4.44 & 2.96 & $4 \cdot 44$ \\
\hline A. 583 & 4 & $40-50$ & $0 \cdot 10$ & $18 \cdot 4$ & 0.54 & $0 \cdot 16$ & $18 \cdot 4$ & $14 \cdot 8$ \\
\hline A. 570 & 4 & $20-30$ & 0.48 & $16 \cdot 0$ & $5 \cdot 3$ & $1 \cdot 43$ & 16.0 & $16 \cdot 0$ \\
\hline A. 571 & 4 & $20-30$ & $1 \cdot 5$ & $18 \cdot 4$ & $5 \cdot 4$ & $3 \cdot 6$ & $14 \cdot 2$ & $15 \cdot 8$ \\
\hline
\end{tabular}


measurement; ethanol was used, as the absorption spectra did not vary greatly with solvent and the addition of ethanol gave clear solutions.

The antibiotic contents of the culture filtrates and mycelial extract samples were estimated by an agar cup-plate assay with Saccharomyces cerevisiae as the test organism. For the first extract of each antibiotic a sample of culture filtrate was used as an arbitrary assay standard. Usually eñough solid was isolated from this extraction to enable all subsequent work on the antibiotic to be assayed in terms of the solid preparation in $40 \%(\mathrm{v} / \mathrm{v})$ pyridine in water. The minimum inhibitory concentrations against six selected fungi were determined by duplicate serial two-thirds or one-third dilutions in $2 \%$ glucose broth at $\mathrm{pH} 6 \cdot 0: 48 \mathrm{hr}$. broth cultures diluted 1/100 were used as inocula and dilution tubes were incubated at $28^{\circ}$ for $48 \mathrm{hr}$. The test organisms used were Saccharomyces cerevisiae, Aspergillus niger, Mucor racemosus, Candida albicans, Fusarium culmorum and Trichophyton mentagrophytes.

\section{RESULTS}

In 25 soil samples from various localities 60 polyene antibiotic-producing isolates were found. One isolate produced simultaneously antibiotics in groups 1 and $2 \mathrm{~A}$, another produced antibiotics in groups 1 and 4 , and a third isolate produced antibiotics in groups $1,2 \mathrm{~A}$ and 4. Three isolates produced antibiotics which were not of a polyene nature. In two of these the antibiotic was identified as cycloheximide (Whiffen, Bohonos \& Emerson, 1946) but the third one was not characterized. The locations of the soil samples and the polyene-producing isolates obtained therefrom are given in Table 2, together with the types of polyene they produce. A selection of some results for the minimal inhibitory concentrations of the antibiotics against 6 fungi and yeasts is given in Table 3.

The relative amounts of the antibiotics contained in the mycelia and culture filtrates of the organisms grown in different media were determined by plate assay against Saccharomyces cerevisiae. Whole cultures and culture filtrates were assayed directly, and the mycelia were extracted exhaustively with $80 \%(\mathrm{v} / \mathrm{v})$ acetone in water, the acetone being then removed in vacuo before dilution and addition to the plates. Some of the results are shown in Table 4.

Antibiotics of group 1 assayed as whole culture always gave an accurate assessment of the total antibiotic present, that is, all the antibiotic was available for assay purposes. This was not true of antibiotics in the other groups, where the figures obtained by whole culture assay were always lower than the amount of antibiotic activity recovered by extraction. In these cases part of the antibiotic is held in a bound form by the mycelium and is not available for assay purposes.

\section{DISCUSSION}

It seems from our results that there is a wide distribution throughout the world of streptomycetes which produce polyene antibiotics, though we can draw no conclusions about their abundance. The distribution of polyenes found by us differs markedly from that described by Pledger \& Lechevalier (1956), 
but this is not surprising in view of the limited range of soils they examined. Further, they stated that their method of screening favoured the selection of Streptomyces griseus strains, a limitation that does not apply to our methods of isolation. We think it noteworthy that most antifungal antibiotics revealed by our screening programme are of a polyene nature. The ratio of polyene antibiotics to non-polyene types found was 20 to 1 .

Table 4. Distribution of activity of polyene antibiotics between culture filtrates and mycelia

\begin{tabular}{|c|c|c|c|}
\hline \multirow[b]{2}{*}{ Antibiotic no. } & \multirow[b]{2}{*}{ Polyene type } & \multicolumn{2}{|c|}{ Activity (\%) } \\
\hline & & Culture filtrate & Mycelium \\
\hline A. 284 & 1 & 50 & 50 \\
\hline A. 288 & 1 & 31 & 69 \\
\hline A. 387 & 1 & $\mathbf{0}$ & 100 \\
\hline A. 432 & 1 & 7 & 93 \\
\hline A. 862 & 1 & 67 & 33 \\
\hline A. 228 & $\mathbf{2 A}$ & 55 & 45 \\
\hline A. 341 & $\mathbf{2 A}$ & 78 & 22 \\
\hline A. 786 & $\mathbf{2 A}$ & 57 & 43 \\
\hline A. 789 & $\mathbf{2 A}$ & 24 & 76 \\
\hline A. 246 & $\mathbf{2 B}$ & 40 & 60 \\
\hline A. 772 & $\mathbf{2 B}$ & 47 & $\mathbf{5 3}$ \\
\hline A. 4 & 4 & 40 & 60 \\
\hline A. 571 & 4 & 7 & 93 \\
\hline A. 583 & 4 & 40 & 60 \\
\hline
\end{tabular}

There does not appear to be any correlation of polyene type with geographical location, although the number of soil samples investigated is too small for drawing any firm conclusions. We consider any such relationship rather improbable in view of the general kind of distribution we have found. Further, the fact that one isolate can produce more than one type of polyene would appear inconsistent with any such relationship, even though all the isolates which produced more than one polyene originated in the Argentine.

The results obtained with the limited number of test organisms used show that there are small differences between antibiotics in the same group and that members of groups $1,2 \mathrm{~A}$ and $2 \mathrm{~B}$ cannot be distinguished by the test organisms used. Group 4 antibiotics differ markedly from those of groups 1, 2A and $2 B$ by their relative inactivity against three of the four filamentous fungi and their high activity against yeasts. In the Saccharomyces cerevisiae plate assay it was noted that antibiotics of groups $1,2 \mathrm{~A}$ and $\mathbf{2 B}$ gave satisfactory doseresponse curves $(2.5 \mathrm{~mm}$. diam. for doubling dilutions) and sharp inhibition zones. Antibiotics of group 4 and the one group 3 antibiotic gave poor doseresponse curves (about $1.5 \mathrm{~mm}$. for doubling dilutions) and zones with diffuse edges. A point of distinction between antibiotics of group 1 and those of the other groups was in the reliability of the whole culture assay values. Whereas the group 1 antibiotics always gave reliable results when the cultures were assayed on plates, the members of the other groups generally gave by this assay figures well below the true antibiotic contents of the cultures, as determined by extractions. However, there was no relationship between the type 
of polyene and the distribution of activity between culture filtrate and mycelium. The widely differing values for the proportions of antibiotic in culture filtrates and mycelia, and in particular the high filtrate contents, are somewhat surprising, since the pure antibiotics have low solubilities in water. It would have appeared reasonable to expect accumulations of the antibiotics in the mycelia, but this did not occur, and there must be active solubilizing agents present in culture media used.

\section{REFERENCES}

Davisson, J. W., Tanner, Jr., F. W., Finlay, A. C. \& Solomons, I. A. (1951). Rimocidin, a new antibiotic. Antibiot. \& Chemother. 1, 289.

Hazen, E. L. \& Brown, R. (1951). Fungicidin, an antibiotic produced by a soil Actinomycete. Proc. Soc. exp. Biol., N.Y. 76, 93.

Hickey, R. J., Corum, C. J., Hidy, P. H., Cohen, I. R., NAger, U. F. B. \& Kropp, E. (1952). Ascosin, an antifungal antibiotic produced by a Streptomycete. Antibiot. \& Chemother. $2,472$.

Hosoya, S., Komatsu, N., Soeda, M. \& Sonoda, Y. (1952). Trichomycin, a new antibiotic produced by Streptomyces hachijoensis with trichomonadicidal and antifungal activity. Jap. J. exp. Med. 22, 405.

Lechevalier, H., Acker, R. F., Corke, C. T., Haenseler, C. M. \& Waksman, S. A. (1953). Candicidin, a new antifungal antibiotic. Mycologia, 45, 155.

Okami, Y., Wahara, R., Nakamura, S. \& Umezawa, H. (1954). Studies on antibiotic Actinomycetes. IX. J. Antibiot. Japan, A, 7, 98.

Oroshnik, W., Vining, L. C., Mebane, A. D. \& Taber, W. A. (1955). Polyene antibiotics. Science, 121, 147.

Oswald, E. J., ReEDY, R. J. \& RaNDall, W. A. (1956). An antifungal agent, 1968, produced by a new Streptomyces species. Antibiotics Annual, 1955-6, p. 236. New York Medical Encyclopaedia Inc.

Pledger, R. A. \& Lechevalier, H. (1956). Survey of the production of polyenic substances by soil Streptomycetes. Antibiotics Annual, 1955-6, p. 249. New York Medical Encyclopaedia Inc.

Raubitschek, F., Acker, R. F. \& Waksman, S. A. (1952). Production of an antifungal agent of the fungicidin type by Streptomyces aureus. Antibiot. \& Chemother. 2, 179.

Shibata, M., Honjo, M., Tokui, Y. \& Nakazawa, K. (1954). On a new antifungal and antiyeast substance, Candimycin, produced by a Streptomyces. J. Antibiot. Japan, B, 7, 168.

Swart, E. A., Romano, A. H. \& Waksman, S. A. (1950). Fradicin, an antifungal agent produced by Streptomyces fradiae. Proc. Soc. exp. Biol., N.Y. 73, 376.

Taber, W. A., Vining, L. C. \& Waksman, S. A. (1954). Candidin, a new antifungal antibiotic produced by Streptomyces viridoflavus. Antibiot. \& Chemother. 4, 455.

Takahashi, I. (1953). A new antifungal substance, flavacid. Studies on the antibiotic substances from Actinomycetes, XXVII. J. Antibiot. Japan, A, 6, 117.

Tytell, A. A., McCarthy, F. J., Fisher, W. P., Bolhofer, W. A. \& Charney, J. (1955). Fungichromin and Fungichromatin: new polyene antifungal agents. Antibiotics Annual 1954-5. p. 716. New York Medical Encyclopaedia Inc.

Utahara, R., Okami, Y., Nakamura, S. \& Umezawa, H. (1954). On a new antifungal substance, Mediocidin, and other antifungal substances of Streptomyces with three characteristic absorption maxima. J. Antibiot. Japan, A, 8, 120.

Vandeputte, J., WAchtel, J. L. \& Stiller, E. T. (1956). Amphotericins A and B, antifungal antibiotics produced by a Streptomycete. II. The isolation and properties of the crystalline amphotericins. Antibiotics Annual 1955-6, p. 587. New York Medical Encyclopaedia Inc. 
Vining, L. C., Taber, W. A. \& Gregory, F. J. (1955). The candidin-candicidin group of antifungal antibiotics. Antibiotics Annual 1954-5, p. 980. New York Medical Encyclopaedia Ina

Wakaki, S., Hamada, K., Akanabe, S. \& Asahina, T. (1953). Studies on the antifungal antibiotic from Streptomyces. IV. On the physico-chemical properties of chromin. J. Antibiot. Japan, A, 6, 145.

Whiffen, A. J., Bohonos, N. \& Emerson, R. J. (1946). The production of an antifungal antibiotic by Streptomyces griseus. J. Bact. 52, 610 .

Whitfield, G. B., Brock, T. D., Amman, A., Gottlieb, D. \& Carter, H. E. (1955). Filipin, an antifungal antibiotic. Isolation and properties. J. Amer. chem. Soc. 77, 4799. 